Article

\title{
Relationship between Light Use Efficiency and Photochemical Reflectance Index Corrected Using a BRDF Model at a Subtropical Mixed Forest
}

\author{
Li Ma ${ }^{1,2}$, Shaoqiang Wang ${ }^{1,2, *}$, Jinghua Chen ${ }^{1,2}$, Bin Chen ${ }^{1,2}$, Leiming Zhang ${ }^{1,2}$, Lixia Ma ${ }^{3}$, \\ Muhammad Amir ${ }^{1,2} \oplus$, Leigang Sun ${ }^{4}$, Guoyi Zhou ${ }^{5}$ and Ze Meng ${ }^{5}$ \\ 1 Key Laboratory of Ecosystem Network Observation and Modeling, Institute of Geographic Sciences and \\ Natural Resources Research, Chinese Academy of Sciences, Beijing 100101, China; \\ mali.16b@igsnrr.ac.cn (L.M.); chenjh.14b@igsnrr.ac.cn (J.C.); chenbin@igsnrr.ac.cn (B.C.); \\ zhanglm@igsnrr.ac.cn (L.Z.); mamir2019@igsnrr.ac.cn (M.A.) \\ 2 College of Resources and Environment, University of Chinese Academy of Sciences, Beijing 100049, China \\ 3 State Key Laboratory of Soil and Sustainable Agriculture, Institute of Soil Science, \\ Chinese Academy of Sciences, Nanjing 210008, China; malixia@issas.ac.cn \\ 4 Engineering Research Center for Geographic Information Application, Institute of Geographical Sciences, \\ Hebei Academy of Sciences, Shijiazhuang 050011, China; sunleigang07@mails.ucas.ac.cn \\ 5 South China Botanical Garden, Chinese Academy of Sciences, Guangzhou 510650, China; \\ gyzhou@scib.ac.cn (G.Z.); mengze@scib.ac.cn (Z.M.) \\ * Correspondence: sqwang@igsnrr.ac.cn
}

Received: 11 December 2019; Accepted: 29 January 2020; Published: 7 February 2020

\begin{abstract}
Light use efficiency (LUE) is a key indicator of vegetation photosynthesis, which provides important insights into how vegetation productivity responds to environmental conditions. The photochemical reflectance index (PRI) is based on reflectance at 531 and $570 \mathrm{~nm}$, which reflects the xanthophyll cycle process of plants under different radiation conditions, and makes LUE related to plant optical characteristics. In this study, tower-based PRI and eddy covariance (EC) based LUEs were used to explore the ability of PRI to track LUE variations in a subtropical, evergreen mixed forest in South China. The results indicate that there is a stronger relationship between PRI and LUE, corrected by the bidirectional reflectance distribution function (BRDF), where $\mathrm{R}^{2}=0.46$ before correction and $\mathrm{R}^{2}=0.60$ after correction. Generally, PRI is able to capture diurnal and seasonal changes in LUE. Simultaneously, this study highlights a significant correlation between LUE and PRI, but there is also a large seasonal difference in its correlation. The correlation in winter was significantly stronger than summer. The strongest correlation is found in November $\left(R^{2}=0.91\right)$ and the weakest is in July $\left(R^{2}=0.34\right)$. Photosynthetically active radiation (PAR) had a strong influence on the LUE-PRI relationship, while vapor pressure deficit (VPD) and air temperature (Ta) had negative influences on the relationship between LUE and PRI. Terrestrial laser scanning is used to retrieve the vertical structure of forest crown. Our results show that the vegetation canopy structure (i.e., effective leaf area index, $\mathrm{LAI}_{\mathrm{e}}$ ), extracted from terrestrial laser scanning (TLS) point data in subtropical mixed forests, had a weak influence on LUE. Our research suggests that environmental factors and vegetation canopy structures should be considered when using PRI to accurately estimate LUE.
\end{abstract}

Keywords: photochemical reflectance index; light use efficiency; BRDF; leaf area index

\section{Introduction}

Gross Primary Production (GPP) represents the amount of organic carbon fixed by terrestrial plants through photosynthesis and is the driving force for multiple ecosystem functions [1-3]. An accurate 
understanding of the temporal and spatial dynamics of terrestrial ecosystem GPPs not only deepens the understanding of the mutual feedback of ecosystems and climate systems, but also helps to fully understand the carbon cycle and to formulate policies related to climate change [4-8].

Different ecosystems have different photosynthetic carbon absorption capacities and respond differently to changing environmental conditions. Plant leaves adjust their physiological mechanisms to maintain a balance between daylight photosynthesis and light protection. Light use efficiency (LUE) is determined by environmental factors such as nutrients, moisture, and atmospheric temperature, resulting in differences in time and space in the photochemical reaction process. The photochemical reflectance index (PRI), based on remote sensing technology, provides the possibility to establish a link between changes in LUE and changes in the spectral characteristics of vegetation [9-11]. Some previous studies have shown that LUE is not a constant value in different ecosystems [12]. Some have also reported that vegetation types, nutrients, temperature, soil moisture, and canopy structure complicate the interpretation of LUE [13-18]. Huemmrich et al. (2010) had shown that LUE was most affected by light and is usually reduced under excessive light conditions [19]. Canopy LUE varies with the radiation received by canopy, while PRI also shows similar properties due to its sensitivity to the fraction of shaded or sunlit leaves [20].

PRI has been used widely as a proxy for LUE. PRI is a simple reflectance parameter that can be measured using a spectrometer under natural conditions [21]. First, the spectral changes of PRI are caused by changes in the pigment bank of plant leaves [22]. Secondly, on a daily scale, the change of PRI is driven by the xanthophyll cycle. On a long-term seasonal scale, the change of PRI is driven by the ratio of carotenoid to chlorophyll pigment pools [9,23-25]. Third, some studies have found that there is a good correlation between LUE and PRI in evergreen forests [11].

PRI reflects the optical information of vegetation based on spectrometer observation. It is worth noting that the forest canopy, like most ground features, belongs to the non-Lambertian body, and it will show different degrees of anisotropy. In general, multi-angle remote sensing observations are used to obtain multi-angle information of the vegetation canopy to improve the monitoring and inversion accuracy of crop biochemical parameters [26,27]. Recent studies provided that the eddy covariance (EC) based LUE and PRI, normalized by the bidirectional reflectance distribution function (BRDF) model, can be explored to validate the relationship [11].

However, it is unclear whether PRI can capture LUE changes in subtropical forests, which are also among the most powerful types of carbon sequestration on earth. The lack of data contributes to the uncertainty in the relationship between PRI and LUE in subtropical evergreen coniferous mixed forests [28]. The results of two Northern forest studies in Canada show that the correlations between PRI and LUE are 0.74 and 0.79, respectively [11]. A study on evergreen broad-leaved forests in Malaysia showed that the correlation between PRI and LUE reached $\mathrm{R}^{2}=0.12$. Using different fitting methods, the impact of VPD on the relationship between PRI and LUE was 34\% and 38\% [29]. Zhang et al. research in subtropical coniferous forests showed that the correlation between PRI and LUE at half-hour and daily scales was $20 \%$ and $29 \%$, respectively, and the correlation was small in suitable growth environments [10].

The distribution of leaves in the vegetation canopy will affect the interception of solar radiation and the efficiency of light utilization. Lidar scans can more accurately retrieve vegetation canopy structural parameters [30]. The lidar scanning system scans the target by emitting laser light, and then compares the received signal (target echo) reflected from the target with the transmitted signal. After proper processing, the target's 3D point cloud data can be obtained. Relevant parameters of the target can be extracted based on the point cloud data. Due to the high-density point cloud data obtained by the ground-based lidar scanning system, the canopy structure parameters can be more accurately retrieved, and the horizontal and vertical information of the forest canopy can be detailed [31]. TLS can be used to directly measure tree height, canopy height, above-ground biomass, canopy coverage, forest density, volume, vertical structure, effective leaf area index $\left(\mathrm{LAI}_{\mathrm{e}}\right)$, and gap fraction. The $\mathrm{LAI}_{\mathrm{e}}$ is an important parameter for quantitatively characterizing the vegetation canopy structure [32-36]. 
Therefore, investigating patterns of LUE changes across different canopy structures can provide insights into how differences in forest structure affect LUE [11,37].

In this study, we investigated the relationship between PRI and LUE, obtained from measurements of an AMSPEC spectrometer and eddy covariance (EC) system in a subtropical mixed forest in China. The objectives of this study are: (1) to use the BRDF model to correct the PRI observed by a multi-angle spectrometer; (2) to study the effects of environmental and climatic factors on the relationship between PRI and LUE, and analyze the changes in the relationship between the PRI and LUE; (3) to use the TLS data to extract the vegetation canopy structure parameters, and to determine the influence of the vegetation canopy structure on LUE.

\section{Materials and Methods}

\subsection{Study Area}

The study was carried out in Dinghushan National Nature Reserve, Zhaoqing City, Guangdong Province $\left(112^{\circ} 30^{\prime} 39^{\prime \prime}-112^{\circ} 33^{\prime} 41^{\prime \prime}\right.$ E, $\left.23^{\circ} 09^{\prime} 21^{\prime \prime}-23^{\circ} 11^{\prime} 30^{\prime \prime} \mathrm{N}\right)$, a site of the Chinese Ecosystem Research Network (CERN) and the ChinaFLUX network. The flux tower $\left(23^{\circ} 10^{\prime} 12^{\prime \prime} \mathrm{N}, 112^{\circ} 32^{\prime} 4^{\prime \prime} \mathrm{E}, 240 \mathrm{~m}\right.$ above sea level), located in the core area of Dinghushan Nature Reserve, was established in 2002 (Figure 1). According to long-term records of an adjacent weather station, the annual average temperature and precipitation were $20.9^{\circ} \mathrm{C}$ and $1956 \mathrm{~mm}$, respectively [38,39]. The dry and wet seasons are obvious. Rainfall occurs primarily during the months of April to September, with $80 \%$ precipitation in the whole year. The dry season was from October to March. The type of vegetation was subtropical evergreen conifer and broad-leaved mixed forest. The canopy height was $17 \mathrm{~m}$ and the main tree species were schima root-bark (Schima superba Gardner and Champion), Chinese chestnut (Castanopsjs chinensis Hance) and Chinese red pine (Pinus massoniana Lamb.). The soil taxonomy is red and yellow soils [40,41].
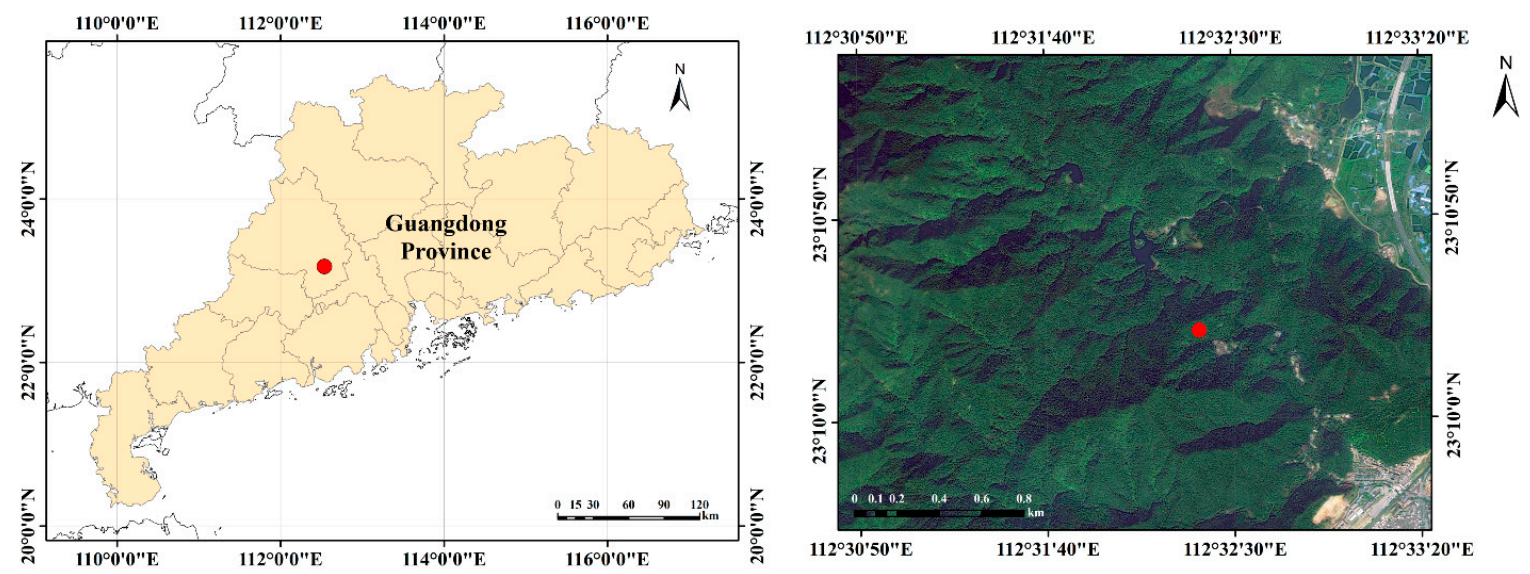

Figure 1. Location of the study site flux tower at the Dinghushan National Nature Reserve, Guangdong Province, China.

\subsection{AMSPEC II Spectral Data}

The vegetation canopy spectral data was obtained from the AMSPEC II spectral observation system which was installed at a flux tower height of $36 \mathrm{~m}$. This was a multi-angle spectral observation system consisting of a UniSpec-DC Spectral Analysis System (PP Systems, Amesbury, MA, USA), upstream fiber, downstream fiber, an automatic tilt rotation, a data transmission system (PTU-D46-17P70T), and a data storage system under the tower. The data storage system continuously archived the multi-angle observations of vegetation canopy spectral reflectivity.

The upstream fiber was used to measure the downward radiation of the sun while the downstream fiber was used to automatically observe the spectral reflectance of the vegetation canopy. The spectral 
range of the spectrometer was 300-1100 $\mathrm{nm}$ with a spectral resolution of $3.3 \mathrm{~nm}$. The range of viewing zenith angle was set as $42^{\circ}$ to $62^{\circ}$ and the viewing azimuth angle was set from $10^{\circ}$ to $160^{\circ}$ and $190^{\circ}$ to $340^{\circ}$ with an angle step of $10^{\circ}$. Data was archived at 15-min intervals over $24 \mathrm{~h}$ each day. In order to analyze the LUE calculated by the EC flux data, the spectral observation data per half-hour was selected from 9:00-17:00 every day during April 2014, to March 2015. First, the spectrometer data was retrieved. Then, the whiteboard correction parameters and the value of the central wavelength were used to control the quality of data. The whiteboard was a standard diffuse reflection reference for measurement. After the outliers were removed, the canopy reflectance at the wavelengths of 531 and $570 \mathrm{~nm}$ were extracted from the archived data. The PRI value was calculated by Equation (1):

$$
P R I=\frac{R_{531}-R_{570}}{R_{531}+R_{570}}
$$

where $R_{531}$ and $R_{570}$ represent the reflectivity of the vegetation canopy at 531 and $570 \mathrm{~nm}$, respectively.

\subsection{The BRDF Model}

The PRI obtained from the AMSPEC observation was affected by the observation angle and physiological status. Assuming that the physiological state and lighting conditions of the plants remained unchanged every $15 \mathrm{~min}$, and followed the method by Hilker et al. (2008a). The kernel-driven BRDF model has been widely used in ground measurement and satellite remote sensing. The semi-empirical kernel-driven model of vegetation canopy BRDF are generally comprised of a linear combination of three kernels describing isotropic, geometric, and volume scattering effects [42]. Isotropic scattering assumes that the leaves in the canopy were randomly distributed and have the characteristics of a Lambertian surface. Geometric optical scattering was due to the shape of the vegetation canopy. Volume scattering described the effect of scattering caused by the inside of the canopy [42]. The BRDF model could be decomposed into the sum of three weights of isotropic scattering, volume scattering, and geometric optical scattering. Among them, the Ross-Thick kernel was used for volume scattering, and the Li-Sparse kernel was used for geometrical optical scattering. It can be expressed as:

$$
R\left(\theta_{S}, \theta_{V}, \varnothing\right)=k_{0}+k_{1} F_{1}\left(\theta_{S}, \theta_{V}, \varnothing\right)+k_{2} F_{2}\left(\theta_{S}, \theta_{V}, \varnothing\right)+\ldots+k_{n} F_{n}\left(\theta_{S}, \theta_{V}, \varnothing\right)
$$

where $\theta_{S}, \theta_{V}$, and $\varnothing$ are the solar zenith, view zenith, and relative azimuth angles, respectively, $F_{i}$ are a priori kernels based on either physical or empirical considerations, and $k_{i}$ are coefficients based on the observed value $[11,43]$. We used least square estimation to calculate the corresponding $k_{i}$ for each $F_{i}$.

\subsection{Terrestrial Laser Scanning Data}

In order to extract the canopy structure factors of coniferous and broad-leaved mixed forest around the flux tower of Dinghushan Nature Reserve, a Trimble TX8 terrestrial laser scanner was used to scan the vegetation and to obtain the point cloud data. The scanner utilized a vertical rotating mirror based on a horizontal rotation with a scanning speed of 1 million points/second. The maximum standard measurement range was $120 \mathrm{~m}$, the minimum measurement range was $0.6 \mathrm{~m}$, and the noise of the measurement range was $<2 \mathrm{~mm}$. The angle range of the scanning field was $360^{\circ} \times 317^{\circ}$.

The forest canopy structure was scanned and a total of six stations were arranged. The distance between every two stations was greater than $10 \mathrm{~m}$ (Figure 2). More than three target balls were placed between every two stations, and the three balls were not in the same row. The target ball was used as the feature point; the point cloud data stitching and registration between the two stations were completed. The point cloud data collected by the TLS scanning was like a hemispherical sphere with angular information. With the spectrometer at the center, the points within a radius of $10 \mathrm{~m}$ were selected for extraction of $\mathrm{LAI}_{\mathrm{e}}$. First, the TLS data was divided into different parts according to the azimuth angle of $45^{\circ}$. Second, we visually resolved each part and manually measured the height of 
the highest point on the ground, and manually removed the highest point and the points below the highest point. Finally, the residual points of the 3D point cloud data were projected onto the XOY plane. Third, the porosity of each part was calculated by the volume element method, and the second part of $\mathrm{LAI}_{\mathrm{e}}$ was calculated. Among them, based on Beer's law, the extinction coefficient was set to 0.5. In order to explore the effects of vegetation canopy structure on PRI and LUE, the $\mathrm{LAI}_{e}$ under different classifications were calculated by the TLS data; the PRI spectral observation data of each record was graded based on the observed azimuth, divided into one every $45^{\circ}$, and sliding was performed at an average of $10^{\circ}$; there were 33 levels.

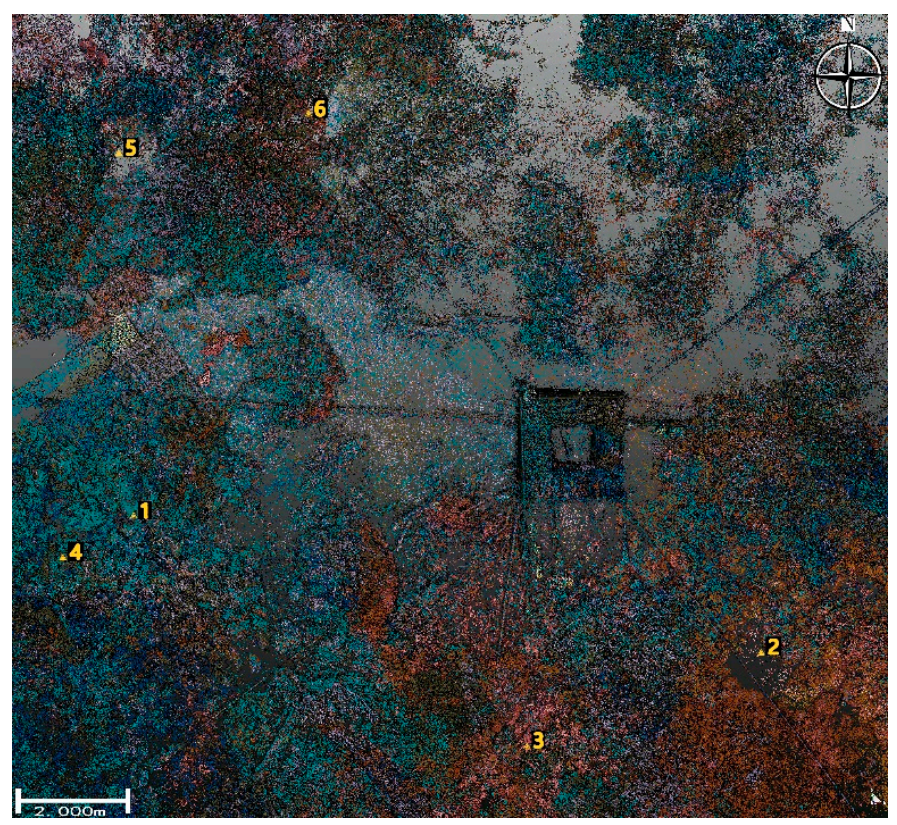

Figure 2. Distribution of the TLS scanning stations.

\subsection{Eddy Covariance Measurement and the LUE Calculation}

The flux tower was installed at $27 \mathrm{~m}$, consisting of a three-dimensional ultrasonic anemometer (CSAT3, Campbell Scientific Ltd., Logan, UT, USA) and fast response infrared $\mathrm{CO}_{2} / \mathrm{H}_{2} \mathrm{O}$ analyzer (Li-7500, Li-CorInc., Lincoln, NE, USA) composition. The $\mathrm{CO}_{2}$ and $\mathrm{H}_{2} \mathrm{O}$ flux data were automatically archived with a CR500 data logger at a frequency of $10 \mathrm{~Hz}$, and the average flux data was calculated at 30 min intervals. In addition, meteorological measurements above the vegetation canopy included canopy incident radiation, air temperature, saturated water vapor pressure, precipitation, soil moisture, etc. The net $\mathrm{CO}_{2}$ exchange (NEE) was calculated from the $\mathrm{CO}_{2}$ storage flux and turbulent flux obtained from flux observations, and the ecosystem respiration $(\mathrm{Re})$ was obtained using an empirical relationship between nighttime requirements at a $50 \mathrm{~mm}$ depth and at soil temperature. Re is the ecosystem respiration during the day, obtained by deducting the exponential relationship between NEE at night and soil temperature at a $5 \mathrm{~cm}$ depth. GPP and LUE were estimated using the following equations:

$$
\begin{gathered}
G P P=R_{e}-N E E \\
L U E=G P P /(P A R * F P A R)
\end{gathered}
$$

Photosynthetically active radiation $(P A R)$ refers to the incident radiation at the top of the vegetation canopy, which can usually be obtained from meteorological observations. A fraction of the absorbed photosynthetically active radiation $(F P A R)$ refers to the ratio of $P A R$ absorbed by the green part of the 
vegetation canopy to total the PAR. It can be obtained from remote sensing data [5,44]. FPAR can be calculated as follows:

$$
F P A R=\frac{\left(N D V I-N D V I_{\min }\right)\left(F P A R_{\max }-F P A R_{\min }\right)}{N D V I_{\max }-N D V I_{\min }}+F P A R_{\min }
$$

where $N D V I_{\min }$ and $N D V I_{\max }$ are NDVI values for vegetation coverage of $5 \%$ and $98 \%$, respectively. According to the characteristics of the vegetation canopy structure in the observation area, $N D V I_{\min }=0.01$, and $N D V I_{\max }=0.5 . F P A R_{\min }$ and $F P A R_{\max }$ represent the minimum and maximum FPAR values, respectively, which are generally assumed to be 0.001 and 0.95 , respectively. The FPAR was obtained by the normalized difference vegetation index (NDVI) estimation method [44], and the vegetation reflectivity in each band was obtained by an automatic multi-angle spectroscopy system. The NDVI can be calculated as follows:

$$
N D V I=\frac{R_{850}-R_{680}}{R_{850}+R_{680}}
$$

where $R_{850}$ and $R_{680}$ represent the reflectance of plant leaves at 850 and $680 \mathrm{~nm}$, respectively, observed by an automated multi-angle spectroscopy system.

\section{Results}

\subsection{Variation of PRI at Different Observation Angles and the Result of BRDF Model}

PRI changed with observation angles; it was correlated with vegetation canopy structures and different environmental factors, produced under different observation angles. Figure 3a shows spectral observations at 10:30-10:45 on 13 July 2014, when the solar azimuth angle was $111^{\circ}$ and the solar zenith angle was about $21^{\circ}$. Figure $3 \mathrm{~b}$ shows spectral observations at 10:30-10:45 on 13 November 2014, when the solar azimuth angle was about $160^{\circ}$ and the solar zenith angle was about $51^{\circ}$. Figure 3a shows that the PRI did not change significantly at different observation angles, which was almost close to each other. Figure $3 b$ shows the variation of PRI from different observation angles. The PRI values in the backward scattering direction were generally higher than the forward scattering direction. When the VAA is about $135^{\circ}$, it is close to the solar incident azimuth angle (called backward scattering direction), and the value of PRI is greater than the VAA of $315^{\circ}$ (forward scattering direction at this time).
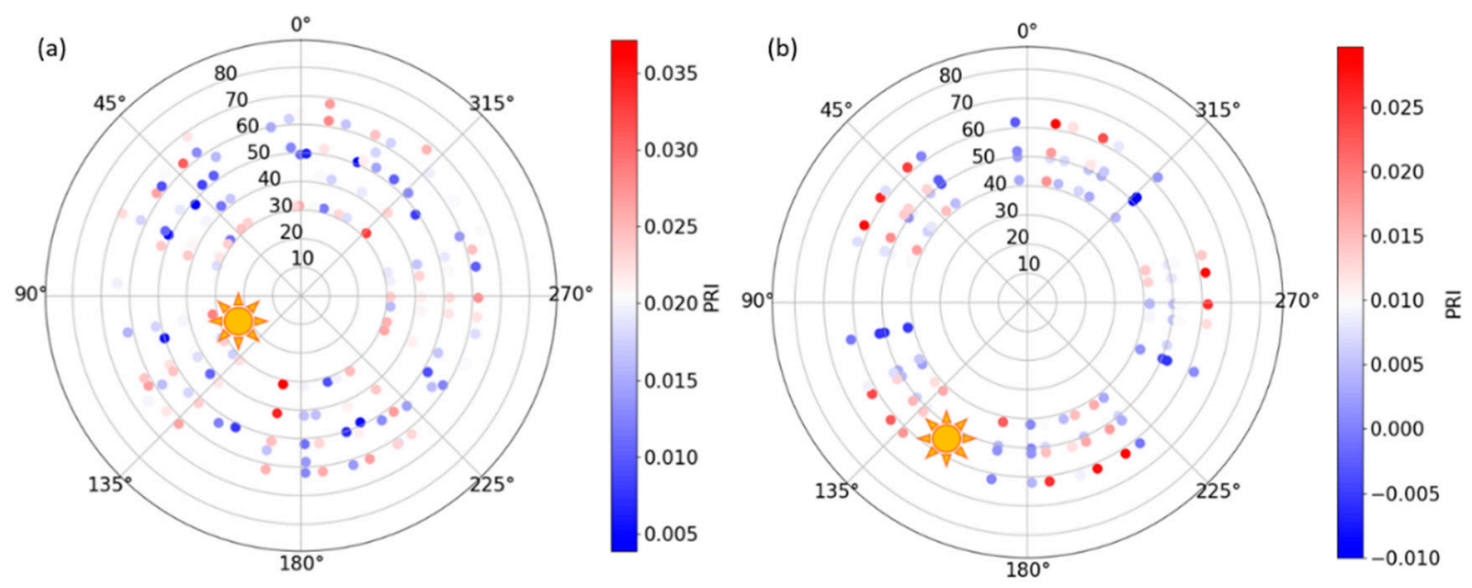

Figure 3. Observed PRI shown in a polar coordinate system (overhead view) obtained during 10:30-10:45 on 13 July 2014 (a) and on 13 November 2014 (b), respectively. The yellow signs represent the solar position in the hemisphere, which is described by the solar azimuth angle (SAA) and solar zenith angle (SZA). The PRI was obtained at different viewing zenith angles (VZA: ranged from 0-90 ${ }^{\circ}$ ) with varied viewing azimuth angles (VAA: ranged from $0-360^{\circ}$ ). 
Figure 4 shows the comparisons of the relationships between the EC-based LUE and PRI with $\left(\mathrm{R}^{2}=0.60, p<0.01\right)$ and without $\left(\mathrm{R}^{2}=0.46, p<0.01\right)$ the correction of the BRDF model at a half-hourly time scale. The red lines represent the linearly fitted functions, and the green lines represent the exponentially fitted functions. The exponential fitting does not differ significantly from the linear adjustment.
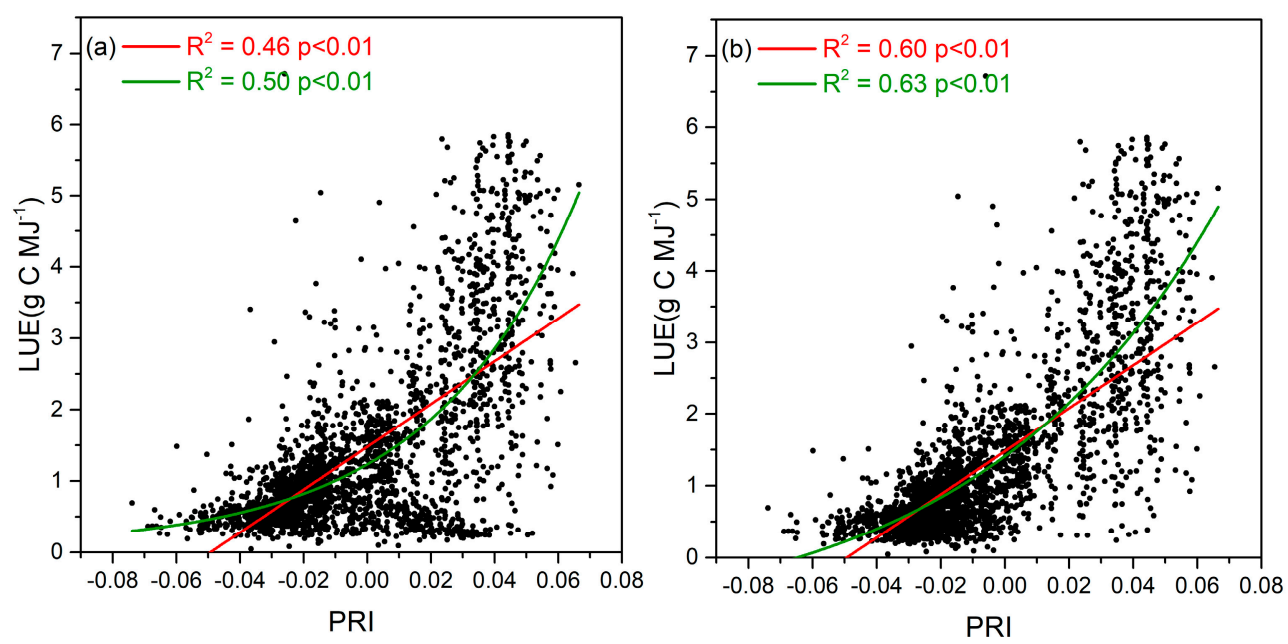

Figure 4. Comparison of the relationship between the LUE and the PRI not corrected by a BRDF model (a) and that between the LUE and the PRI corrected by a BRDF model (b) in the LUE and PRI data were measured every half-hour from April 2014 to March 2015. The red lines represent the linearly fitted functions, and the green lines represent the exponentially fitted functions.

\subsection{Seasonal Variation of PRI, LUE, GPP, and Environmental Factors}

Figure 5 illustrates the continuous variations of PRI, LUE, environmental factors (air temperature (Ta), vapor pressure deficit (VPD), and PAR), and GPP on a half-hour scale. Figure 4a shows the continuous variations of the PRI and LUE. There was a gap of the PRI from 22 March 2014, to 4 April 2014, due to instrument failure. The seasonal variations of LUE and PRI are complicated. During 14 July 2014, to 28 September 2014, PRI and LUE show a steady fluctuation trend. The PRI decreases with temporal change patterns to a very low value in early October. Afterwards, the trend of PRI becomes more obvious, it increases around 28 September 2014, and begins to decrease after 8 November 2014, and then quickly decreases in 23 November 2014, and decreases to the minimum. LUE is generally steadily fluctuating; the values of LUE remain high from 27 October 2014, to 6 December 2014. The temperature reached a peak on 31 July 2014, and then continued to decrease. Until 27 November 2014, the temperature rose slightly. From January to March 2015, the temperature was low and fluctuated slightly. The VPD was lower from November 2014 to March 2015. At other times, it is basically at a higher value, about $100 \mathrm{hPa}$. The value of PAR in the whole year is relatively high from June to October, and the maximum value is concentrated at $451 \mathrm{~J} \mathrm{~m}^{-2} \mathrm{~s}^{-1}$, which was recorded on 4 July 2014. From November 2014 to March of the next year, the maximum value of PAR is $337 \mathrm{~J} \mathrm{~m}^{-2} \mathrm{~s}^{-1}$, which was recorded on 28 March 2015. From the beginning of April 2014, GPP climbed up steadily and reached the peak level during the end of the June 2014 until the middle of the July 2014. After that, GPP dropped down quickly during the end of July to the start of August 2014. While this process had a rebound in September and October 2014, the decline continued until December 2014. In the next year, it dropped to the bottom in March 2015. Definitely, the maximum value of GPP reached to $0.6 \mathrm{~g} \mathrm{C} \mathrm{m}^{-2} \mathrm{hh}^{-1}$ in April, May, August, November, and December 2014, as well as in March 2015. In July, September, and October, the maximum value of GPP is about twice the value of the previous months. 

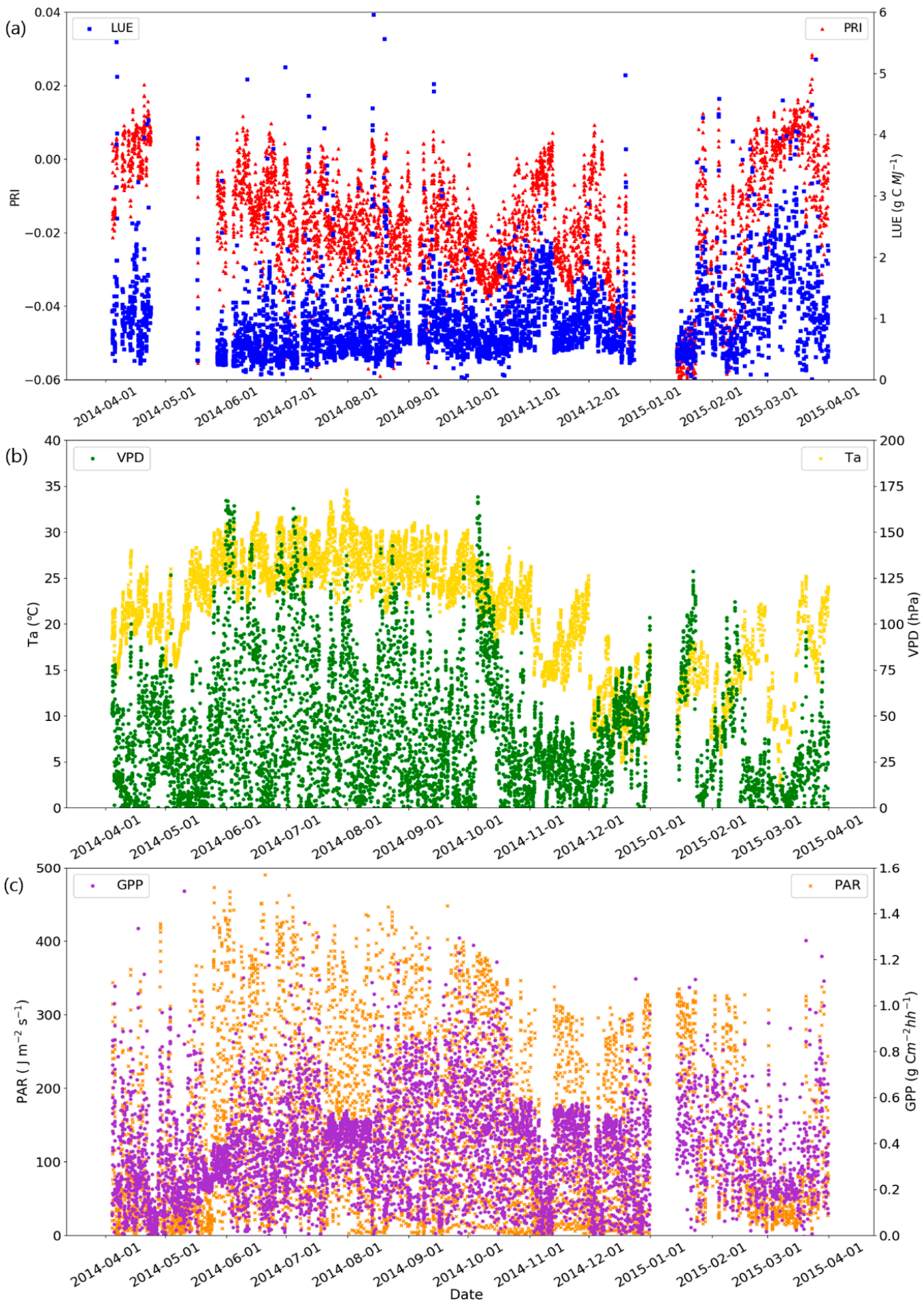

Figure 5. Seasonal changes in PRI and LUE (a), Ta and VPD (b), and PAR and GPP (c) per half-hour was selected from 9:00-17:00 in half-hour intervals every day from April 2014, to March 2015.

\subsection{Temporal Variation of the Relationship between PRI and LUE}

Generally, PRI and LUE are positively correlated, and there is a negative correlation on rare days $(\mathrm{R}<0)$ (Figure 6). During 288 days, PRI and LUE were significantly associated for 84 days $(\mathrm{R}>0.75)$. Overall, from 6 April 2014, to 1st August, 2014, the correlations of PRI and LUE start to decrease and then increase, then the correlations slightly decrease around 1 August 2014, and increase and stabilize from 24 August 2014, to 8 October 2014. Between 8 October 2014, and 7 November 2014, the 
correlations are mostly at a lower value, which increase after 9 November 2014, and remain stable until the end of the year. The correlation value from January to March in the second year is slightly lower than the value at the end of the previous year.

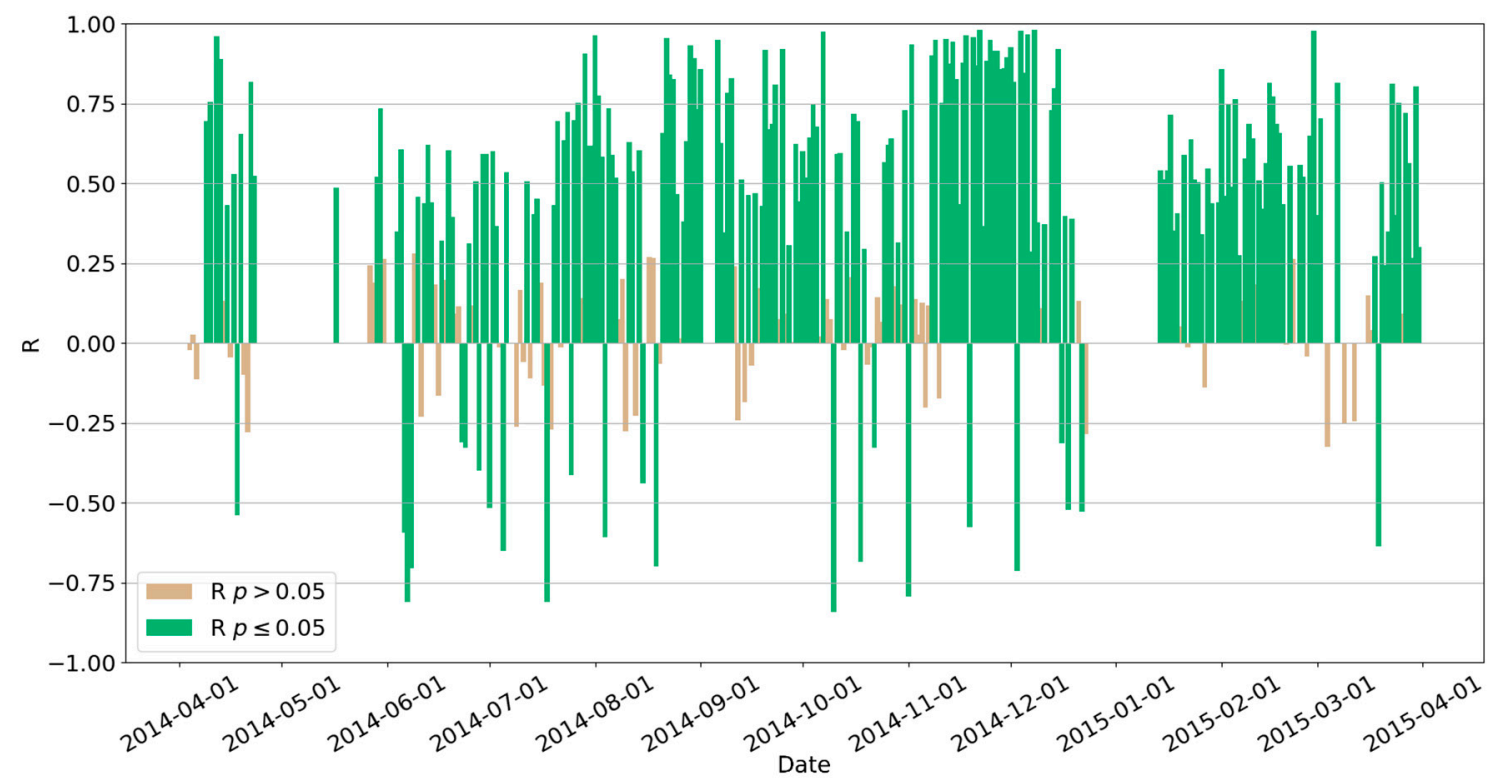

Figure 6. The correlation between daily PRI and LUE for each day from April 2014 to March 2015.

During each month, there are some differences in the relationship between PRI and LUE (Table 1). The linear correlations between PRI and LUE are the smallest from June to August. The smallest correlation occurred in July $2014\left(R^{2}=0.34\right)$, followed by June, $2014\left(R^{2}=0.36\right)$. However, a strong correlation occurred between September and December $2014\left(R^{2}>0.66\right)$, with the largest correlation in November $2014\left(R^{2}=0.91\right)$. The correlations between April and May 2014 were intermediate. PRI can be a good indicator of LUE from September and December 2014.

Table 1. The relationship between PRI and LUE from April 2014 to March 2015 for each month.

\begin{tabular}{cccc}
\hline Mon & $\mathbf{R}^{\mathbf{2}}$ & $p$ & RMSE \\
\hline April & 0.53 & $p<0.01$ & 1.07 \\
May & 0.49 & $p<0.01$ & 0.66 \\
June & 0.36 & $p<0.01$ & 0.78 \\
July & 0.34 & $p<0.01$ & 0.91 \\
Aug & 0.51 & $p<0.01$ & 1.12 \\
Sept & 0.71 & $p<0.01$ & 0.90 \\
Oct & 0.66 & $p<0.01$ & 0.80 \\
Nov & 0.91 & $p<0.01$ & 1.11 \\
Dec & 0.72 & $p<0.01$ & 1.03 \\
Jan & 0.75 & $p<0.01$ & 2.33 \\
Feb & 0.68 & $p<0.01$ & 2.74 \\
March & 0.48 & $p<0.01$ & 3.22 \\
\hline
\end{tabular}

\subsection{The Effects of Environmental Factors on the Correlation between PRI and LUE}

Table 2 shows the response of LUE and PRI to PAR, VPD, and Ta in the wet season (from April 2014 to September 2014) and dry season (from October 2014 to March 2015). In the dry season, LUE was affected differently by PAR, VPD, and Ta, among which PAR had the greatest impact on LUE $\left(\mathrm{R}^{2}=0.85\right)$, followed by VPD $\left(\mathrm{R}^{2}=0.26\right)$, and the effect of Ta on LUE can be ignored. In the wet season, PAR had the greatest effect on LUE $\left(\mathrm{R}^{2}=0.58\right)$. VPD and Ta had no significant difference in its affects 
on LUE. The correlation of LUE and PAR was higher in the dry season than in the wet season. In the dry season, similar to the response of LUE, PRI had the greatest response to PAR $\left(R^{2}=0.67\right)$, and VPD had the second greatest effect on PRI $\left(R^{2}=0.24\right)$, while temperature had no effect on PRI (Table 2). In the wet season, the responses of PRI to PAR and Ta were more obvious $\left(R^{2}=0.59\right.$ and $\left.R^{2}=0.55\right)$, while VPD had a weaker effect on PRI $\left(R^{2}=0.29\right)$. Overall, LUE and PRI had similar responses to environmental factors.

Table 2. Comparison of responses of PRI and LUE to environmental factors in the dry season and wet season.

\begin{tabular}{ccccc}
\hline \multirow{2}{*}{$\mathbf{R}^{2}$} & \multicolumn{2}{c}{ Dry Season } & \multicolumn{2}{c}{ Wet Season } \\
\cline { 2 - 5 } & PRI & LUE & PRI & LUE \\
\hline PAR & $0.67^{* * *}$ & $0.85^{* * *}$ & $0.59^{* * *}$ & $0.58^{* * *}$ \\
VPD & $0.24^{* * *}$ & $0.26^{* * *}$ & $0.29^{* * *}$ & $0.29^{* * *}$ \\
Ta & $0.00^{* * *}$ & $0.55^{* * *}$ & $0.28^{* * *}$ \\
\hline
\end{tabular}

${ }^{* * *} p<0.001,{ }^{* *} p<0.01,{ }^{*} p<0.05$.

Figure 7a and $b$ illustrate the effects of air temperature on LUE and PRI, observed by an AMSPEC spectrometer. Figure 7c reveals the change in the correlation between the PRI and the LUE as a function of temperature. During the study, the air temperature ranged from $5{ }^{\circ} \mathrm{C}$ to $35^{\circ} \mathrm{C}$. When the air temperature is less than $20^{\circ} \mathrm{C}$, there is no correlation between temperature and LUE and PRI (Figure $7 \mathrm{a}, \mathrm{b}$ ). When the temperature is higher than $20^{\circ} \mathrm{C}$, the LUE decreases gradually with the increase of temperature. The correlation between PRI and LUE increases and then decreases with rising air temperature. When the temperature is between $10^{\circ} \mathrm{C}$ to $15^{\circ} \mathrm{C}$, the correlation between PRI and LUE is at its largest $\left(R^{2}=0.78\right)$. The changes in LUE and PRI, as affected by VPD and the changes in the LUE and PRI as a function of VPD, are shown in Figure 7d-f. LUE and PRI decreased with VPD, and the correlation between PRI and LUE decreased with increasing VPD. When VPD $<0.5$, the best correlation between PRI and LUE $\left(R^{2}=0.22\right)$ occurred. When VPD ranges from 1.5 and 2 , there is no correlation between LUE and PRI.
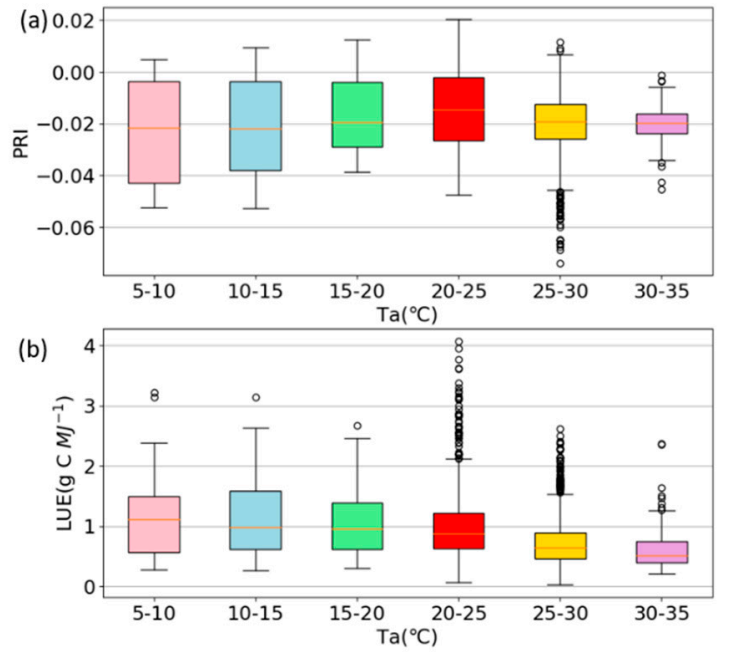

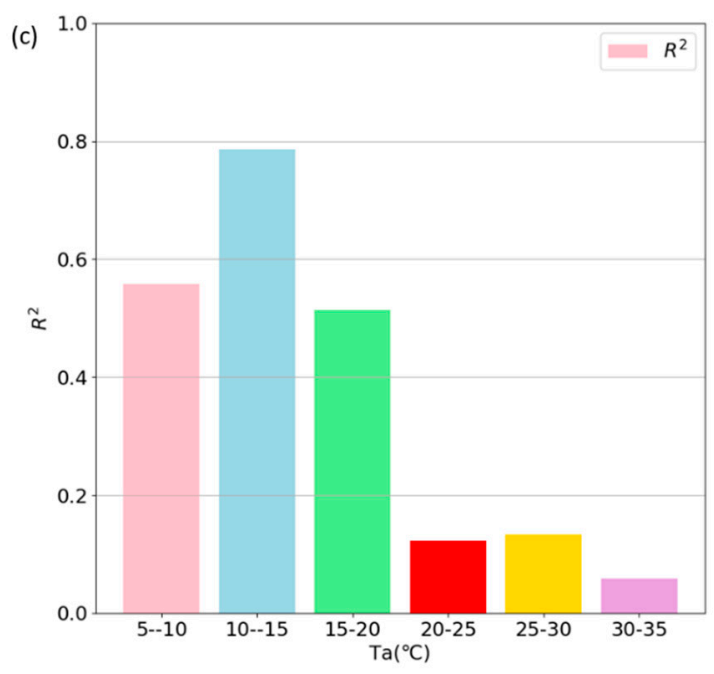

Figure 7. Cont. 


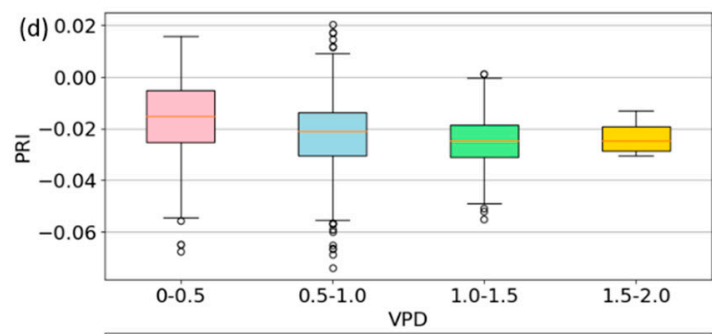

(e)

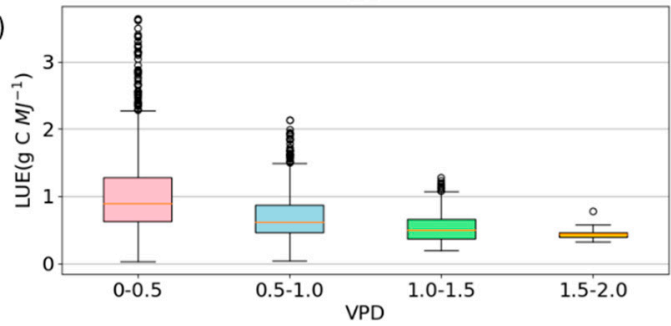

(f)

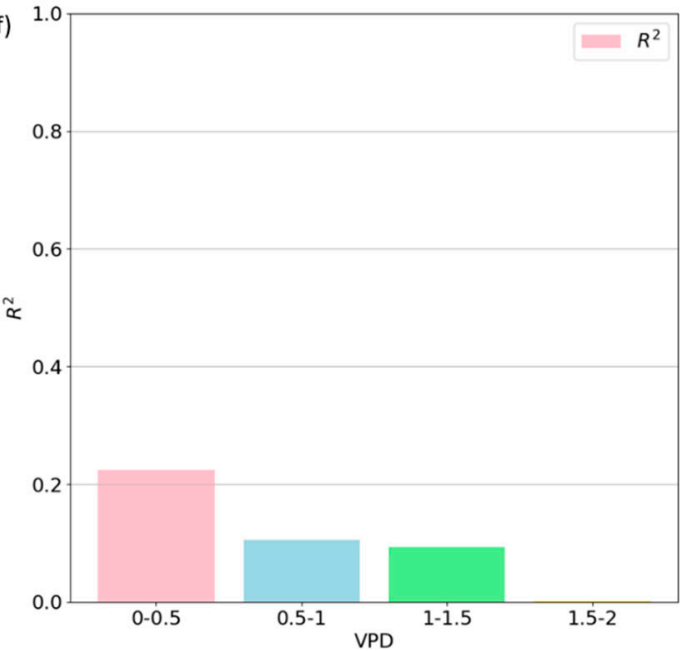

Figure 7. The half-hour time scale of PRI and LUE are as affected by Ta and VPD $(\mathbf{a}, \mathbf{b}, \mathbf{d}, \mathbf{e})$. Correlation between PRI and LUE under different temperatures and VPD gradings $(\mathbf{c}, \mathbf{f})$.

Figure 8 shows the overall pattern of LUE simultaneously responding to air temperature, VPD, and PAR. Different temperature conditions may correspond to different radiation conditions, and different air humidity. Additionally, it was also established, in turn, that LUE showed a decreasing trend when radiation increases. The LUE also decreased slightly with the increase of VPD. However, LUE was not affected by air temperature.
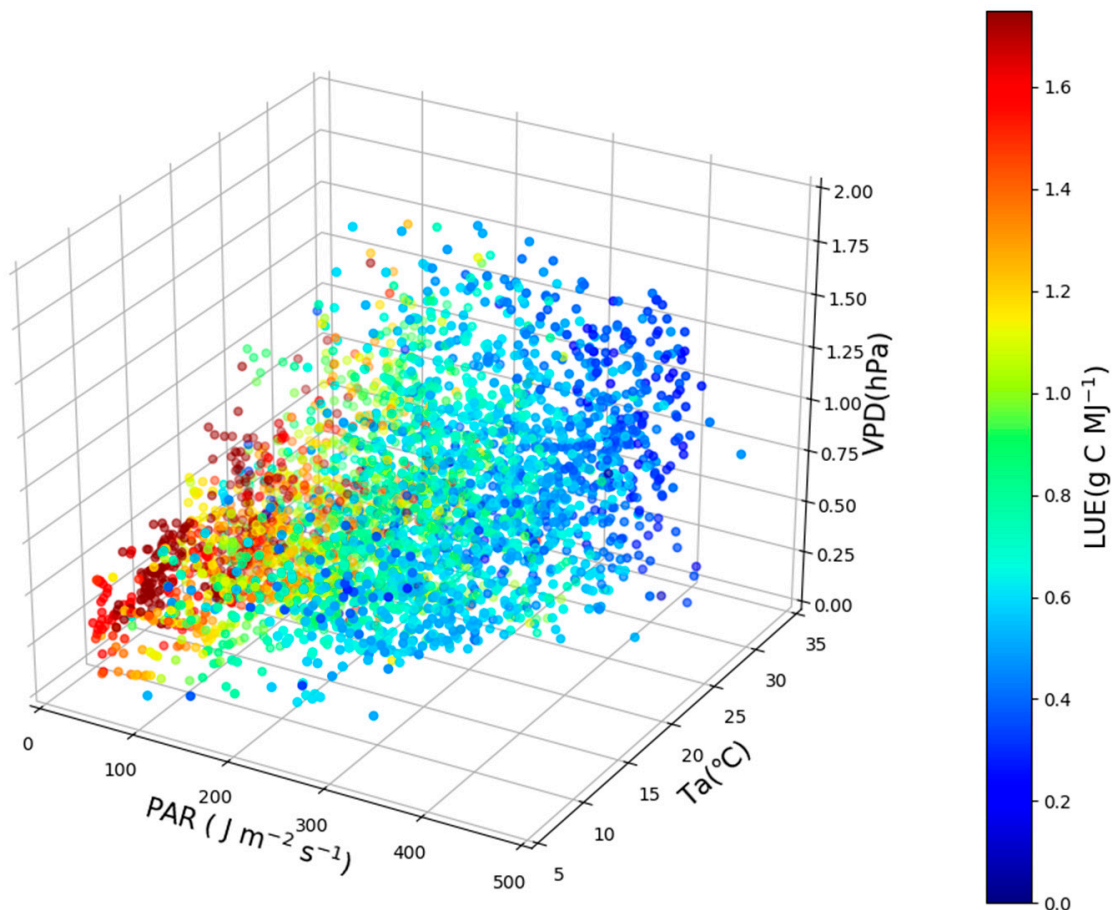

Figure 8. Relationship between Ta, VPD, PAR, and EC-based LUE. Multiple points show identical values that are placed overlapping each other.

\subsection{Effects of Canopy Structural Complexity}

The results of forest canopy structure parameters are shown in Table 3. In the azimuth angle of $0-360^{\circ}$, the forest canopy structure showed an obvious difference in spatial space. Table 3 lists the spatial distribution of $\mathrm{LAI}_{e}$ and LUE. The space usage data of LUE is predicted by AMSPEC-PRI. The 
spatial distribution is slightly different. Figure 9 illustrates the relationship between $\mathrm{LAI}_{\mathrm{e}}$ and LUE. Obviously, as the $\mathrm{LAI}_{e}$ increases, the LUE decreases slightly and then increases $\left(\mathrm{R}^{2}=0.13, p=0.07\right)$.

Table 3. Distribution of gap fraction, $\mathrm{LAI}_{e}$, and LUE in different azimuth angles.

\begin{tabular}{|c|c|c|}
\hline View Azimuth Angle $\left(^{\circ}\right)$ & $\mathrm{LAI}_{\mathrm{e}}$ & $\operatorname{LUE}\left(\mathrm{gC} \mathrm{MJ}^{-1}\right)$ \\
\hline $0-45$ & 1.401 & 2.116 \\
\hline $10-55$ & 1.229 & 2.091 \\
\hline $20-65$ & 1.294 & 2.052 \\
\hline $30-75$ & 1.283 & 2.037 \\
\hline $40-85$ & 1.365 & 2.025 \\
\hline $50-95$ & 1.245 & 2.013 \\
\hline 60-105 & 1.164 & 2.014 \\
\hline $70-115$ & 1.253 & 1.991 \\
\hline $80-125$ & 1.679 & 1.972 \\
\hline $90-135$ & 1.942 & 1.965 \\
\hline $100-145$ & 2.068 & 1.951 \\
\hline $110-155$ & 1.906 & 1.956 \\
\hline $120-165$ & 1.870 & 1.974 \\
\hline $130-175$ & 2.087 & 2.005 \\
\hline 140-185 & 2.509 & 1.999 \\
\hline 150-195 & 3.249 & 2.173 \\
\hline $160-205$ & 3.688 & 2.210 \\
\hline $170-215$ & 3.729 & 2.306 \\
\hline $180-225$ & 3.153 & 2.206 \\
\hline $190-235$ & 2.204 & 2.143 \\
\hline $200-245$ & 1.608 & 2.082 \\
\hline $210-255$ & 1.618 & 2.082 \\
\hline $220-265$ & 1.752 & 1.999 \\
\hline $230-275$ & 2.340 & 1.994 \\
\hline $240-285$ & 3.644 & 2.007 \\
\hline $250-295$ & 4.236 & 1.989 \\
\hline $260-305$ & 3.215 & 1.988 \\
\hline $270-315$ & 2.831 & 1.981 \\
\hline $280-325$ & 2.814 & 1.981 \\
\hline $290-335$ & 3.079 & 2.022 \\
\hline $300-345$ & 3.367 & 2.030 \\
\hline 310-355 & 3.508 & 2.065 \\
\hline $320-360$ & 2.595 & 2.061 \\
\hline
\end{tabular}

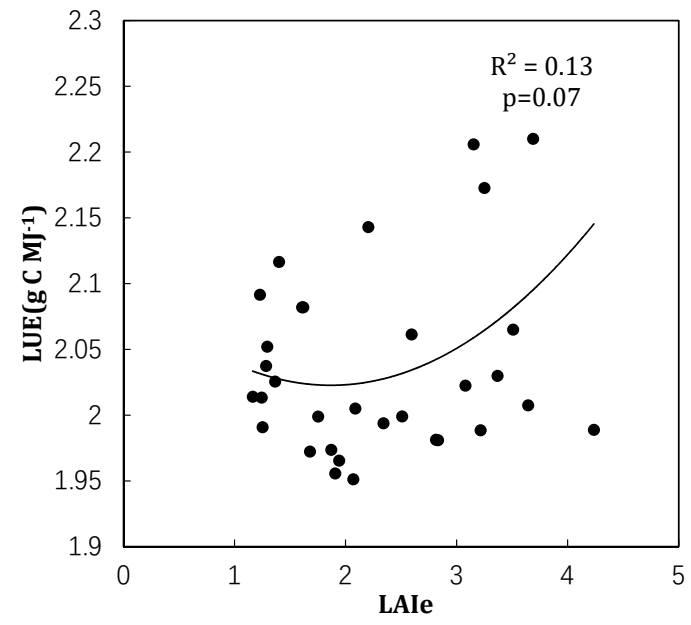

Figure 9. The relationship between AMSPEC-PRI predicted LUE and $\mathrm{LAI}_{\mathrm{e}}$, which were extracted from TLS point cloud in different VAAs. 


\section{Discussion}

\subsection{BRDF Model Correction}

The heterogeneity of the forest canopy structure resulted in directional spectroscopic observations of the vegetation canopy reflectivity. Compared to the traditional vertical observation method, using multi-angle observations makes it easier to capture the spatial structure characteristics of the vegetation canopy. Using the BRDF model correction, the spatial structure characteristics of vegetation can be more accurately observed through spectral observations [45], can eliminate the uncertainty brought by the sun and observation angles, and increase the comparability of different observations. Both the observation angle and the sun angle were changed before the model was corrected. The changing angle will cause the variance of the observation data to increase. After the model is corrected, the angle is fixed, the uncertainty caused by the angle factor will no longer exist, and the estimation accuracy of the LUE and PRI will be improved [11]. This result is also consistent with the results obtained by Jia et al. [11]. Compared with the results obtained by Jia et al., the $\mathrm{R}^{2}$ of exponential adjustment in our study is lower. This may be due to the different types of forests. However, spectroscopic observations are also affected by environmental factors such as radiation and temperature, which are also factors that affect the accuracy of PRI in estimating LUE [10,24,45-47].

\subsection{Response of PRI and LUE to Environmental Factors}

The growth environment (light intensity, temperature, and moisture) in which the plant is located affects the physiological state of the plant [38]. For subtropical evergreen forests, PRI and LUE exhibit very complex changes due to the changing weather environment. During the whole study period, PRI showed a significant correlation with LUE (Figure 4). Significant positive correlations between PRI and LUE were found on some days (Figure 5), months (Table 1), as well as throughout the study period (Figure 5). These results are consistent with previous studies conducted on canopy scales and different temporal scales $[10,11,25,43,47]$. PRI can be used to track LUE in subtropical evergreen coniferous and broad-leaved mixed forest. PRI can be used to track LUE in subtropical evergreen coniferous and broad-leaved mixed forests. A better correlation between PRI and LUE requires seasonal and monthly scale analysis (Figure 6 and Table 1). Obviously, the correlation between PRI and LUE in the dry season is higher than that in the wet season. From April to March of the next year, the correlation between PRI and LUE shows a trend of decreasing first and then increasing. The relationship between the PRI and LUE is mainly affected by environmental factors. Among them, radiation is the main driver of plant photosynthesis, and vegetation has higher photosynthesis under high light and optimal temperature conditions (Table 2). This is consistent with previous results [11]. However, under low radiation conditions, high LUE in plants was observed, which represented the best physiological growth state of vegetation light energy utilization. In contrast, LUE was lower under higher radiation conditions. At the same time, when the vegetation is in the optimal temperature condition, the radiation intensity increases, while the LUE decreases. Therefore, during the study period, the half-hour scale observation of radiation intensity plays a dominant role, in comparison to the temperature. This conclusion is consistent with the results reported by Jia et al. (2008). While illumination is the determinant of the correlation between PRI and LUE, in the dry season, PRI and LUE are also sensitive to VPD. For example, as VPD increases, LUE also increases, indicating that LUE is limited to a certain extent to a high VPD environment. This is consistent with the results of Zhang Qian et al. (2015) [10]. The difference is that PRI and LUE are not affected by temperature during the dry season, indicating that the temperature does not interfere with the characterization of LUE by PRI. Therefore, in the subtropical evergreen coniferous and broad-leaved mixed forest, both radiation and VPD will become important factors affecting the relationship between PRI and LUE. The different meteorological conditions corresponding to different months alter the relationship between PRI and LUE. For subtropical forests, finding an empirical equation for the relationship between PRI and LUE for a full growing season is still a problem. 
In our study, compared to temperate deciduous forests, the $\mathrm{LAI}_{\mathrm{e}}$ changes in the subtropical mixed forests in the Dinghushan area are small [40], the phenological changes are not significant, and the changes in pigment content in the leaves of subtropical coniferous and broad-leaved mixed forests are small. This is the reason why there is a weak dynamic change of LUE.

\subsection{Effects of Vegetation Canopy Structure on LUE}

For subtropical mixed forests, canopy structure is not a main factor affecting LUE change. The estimation of PRI is complicated by the light conditions in the tree crown, especially for the closed crown with complex light conditions, which affects the estimation of LUE [48]. Therefore, we attempted to combine optical data with lidar data in order to infer the impact of forest structure on plant photosynthesis. The spatial distribution difference of $\mathrm{LAI}_{e}$ does not show a great impact on the change of LUE. In our study, we believe that the uneven terrain factors in the study area have an impact on the accuracy of the $\mathrm{LAI}_{\mathrm{e}}$ extracted by the TLS. For the topographic relief, the data of TLS cannot obtain the complete point cloud data of the canopy, especially the upper part of the canopy, which affect the $\mathrm{LAI}_{\mathrm{e}}$ extraction results. In addition, the study area is located in the subtropical region with a humid and hot climate. The cloud layer is thick and has a strong scattering and refraction effect on the solar light [41]. Most of the light reaching the crown is scattered light, which leads to more multiple scatterings and more extensive light conditions $[11,47,48]$. This result is inconsistent with other results $[11,15,49]$. The higher the structural complexity of the canopy, the more it will pass through the canopy, resulting in more light interception, resulting in more multiple scatterings and wider radiation conditions [50-52]. The reason for the inconsistency with the results found by Jia et al (2018) may be that the direct radiation received by the boreal forest is higher than that of tropical forests, and PAR and illumination conditions are one of the most important factors affecting LUE [11].

\section{Conclusions}

Multi-angle tower-based optical spectra data were observed with EC flux data during the period from April 2014 to March 2015 for the purpose of studying the ability of PRI in estimating the LUE of a sub-tropical planted mixed forest stand of Southern China. The following conclusions could be drawn from this study:

1. With the increase of VPD, Ta and PAR, the daily scale PRI, and LUE showed a downward trend, and the response of LUE to changes in these bioclimatic factors were more sensitive than PRI. The correlation of PRI and LUE at half-hour scale was the most significantly affected by PAR, followed by temperature in the wet season. The correlation of PRI and LUE at a half-hour scale was mostly affected by PAR, followed by VPD in the dry season.

2. During the study period, there was a significant linear relationship between LUE and PRI on both the half-hour and daily scale. There was a significant difference in correlation between PRI and LUE throughout the growing season. The correlation was the strongest in November, $2014\left(R^{2}=0.91\right)$, and the weakest in July, $2014\left(R^{2}=0.24\right)$.

3. For subtropical forests, the spatial difference of the canopy is small, and has weak effects on LUE.

In addition to these findings, some shortcomings in our research deserve some attention. For example, the measurements of some pigments (e.g., xanthophyll and chlorophyll) can provide more useful information to further analyze seasonal changes in subtropical mixed forests. In our subsequent work, it will be necessary to pay attention to the influence of the vegetation canopy structure on LUE.

Author Contributions: For research articles with several authors, a short paragraph specifying their individual contributions must be provided. L.M. (Lixia Ma) and S.W. conceived and designed the research; L.M. (Li Ma) conducted the experiments, wrote manuscript, and data analysis; B.C., J.C., and M.A. contributed significantly to the research method and the manuscript revision. L.M. (Lixia Ma) made an important contribution to lidar data processing. L.Z., L.S., G.Z. and Z.M., devoted to data pre-processing. All authors have read and agreed to the published version of the manuscript. 
Funding: This research was supported by the National Key Research and Development Program of China (2016YFA0600202 and 2017YFC0503803), the National Natural Science Foundation of China (41571192 and 41871342).

Acknowledgments: We further acknowledge Qian Zhang (Nanjing University, China) and Mingzhu He (Peking University, China) for their valuable discussions on data processing.

Conflicts of Interest: The authors declare no conflict of interest.

\section{References}

1. Monteith, J.L. Solar radiation and productivity in tropical ecosystems. J. Appl. Ecol. 1972, 9, 747-766. [CrossRef]

2. Field, C.B.; Randerson, J.T.; Malmstrom, C.M. Global net primary production combining ecology and remote sensing. Remote Sens. Environ. 1995, 51, 74-88. [CrossRef]

3. Sun, Y.; Frankenberg, C.; Jung, M.; Joiner, J.; Guanter, L.; Köhler, P.; Magney, T. Overview of Solar-Induced chlorophyll Fluorescence (SIF) from the Orbiting Carbon Observatory-2: Retrieval, cross-mission comparison, and global monitoring for GPP. Remote Sens. Environ. 2018, 209, 808-823. [CrossRef]

4. Baldocchi, D.; Falge, E.; Gu, L.H.; Olson, R.; Hollinger, D.; Running, S.; Anthoni, P.; Bernhofer, C.; Davis, K.; Evans, R.; et al. FLUXNET: A new tool to study the temporal and spatial variability of ecosystem-scale carbon dioxide, water vapor, and energy flux densities. Bull. Am. Meteorol. Soc. 2001, 82, 2415-2434. [CrossRef]

5. Beer, C.; Reichstein, M.; Tomelleri, E.; Ciais, P.; Jung, M.; Carvalhais, N.; Rodenbeck, C.; Arain, M.A.; Baldocchi, D.; Bonan, G.B.; et al. Terrestrial Gross Carbon Dioxide Uptake: Global Distribution and Covariation with Climate. Science 2010, 329, 834-838. [CrossRef]

6. Jung, M.; Reichstein, M.; Margolis, H.A.; Cescatti, A.; Richardson, A.D.; Arain, M.A.; Arneth, A.; Bernhofer, C.; Bonal, D.; Chen, J.Q.; et al. Global patterns of land-atmosphere fluxes of carbon dioxide, latent heat, and sensible heat derived from eddy covariance, satellite, and meteorological observations. J. Geophys. Res.-Biogeosci. 2012, 117, 3. [CrossRef]

7. Houborg, R.; Cescatti, A.; Migliavacca, M.; Kustas, W.P. Satellite retrievals of leaf chlorophyll and photosynthetic capacity for improved modeling of GPP. Agric. For. Meteorol. 2013, 177, 10-23. [CrossRef]

8. Gitelson, A.A.; Gamon, J.A. The need for a common basis for defining light-use efficiency: Implications for productivity estimation. Remote Sens. Environ. 2015, 156, 196-201. [CrossRef]

9. Wong, C.Y.S.; Gamon, J.A. Three causes of variation in the photochemical reflectance index (PRI) in evergreen conifers. New Phytol. 2015, 206, 187-195. [CrossRef]

10. Zhang, Q.; Ju, W.M.; Chen, J.M.; Wang, H.M.; Yang, F.T.; Fan, W.L.; Huang, Q.; Zheng, T.; Feng, Y.K.; Zhou, Y.L.; et al. Ability of the Photochemical Reflectance Index to Track Light Use Efficiency for a Sub-Tropical Planted Coniferous Forest. Remote Sens. 2015, 7, 16938-16962. [CrossRef]

11. Jia, W.; Coops, N.C.; Tortini, R.; Pang, Y.; Black, T.A. Remote sensing of variation of light use efficiency in two age classes of Douglas-fir. Remote Sens. Environ. 2018, 219, 284-297. [CrossRef]

12. Russell, G.; Jarvis, P.; Monteith, J.L. Absorption of radiation by canopies and stand growth. Plant Canopies Their Growth Form Funct. 1989, 31, 21-39.

13. Zarco-Tejada, P.J.; Miller, J.R.; Mohammed, G.H.; Noland, T.L.; Sampson, P.H. Vegetation stress detection through chlorophyll $\mathrm{a}+\mathrm{b}$ estimation and fluorescence effects on hyperspectral imagery. J. Environ. Qual. 2002, 31, 1433-1441. [CrossRef] [PubMed]

14. Middleton, E.M.; Cheng, Y.B.; Hilker, T.; Black, T.A.; Krishnan, P.; Coops, N.C.; Huemmrich, K.F. Linking foliage spectral responses to canopy-level ecosystem photosynthetic light-use efficiency at a Douglas-fir forest in Canada. Can. J. Remote Sens. 2009, 35, 166-188. [CrossRef]

15. Cheng, Y.B.; Middleton, E.M.; Zhang, Q.Y.; Corp, L.A.; Dandois, J.; Kustas, W.P. The photochemical reflectance index from directional cornfield reflectances: Observations and simulations. Remote Sens. Environ. 2012, 124, 444-453. [CrossRef]

16. Lichtenthaler, H.K. The stress concept in plants: An introduction. In Stress of Life: From Molecules to Man; Csermely, P., Ed.; New York Acad Sciences: New York, NY, USA, 1998; pp. 187-198. 
17. Porcar-Castell, A.; Garcia-Plazaola, J.I.; Nichol, C.J.; Kolari, P.; Olascoaga, B.; Kuusinen, N.; Fernandez-Marin, B.; Pulkkinen, M.; Juurola, E.; Nikinmaa, E. Physiology of the seasonal relationship between the photochemical reflectance index and photosynthetic light use efficiency. Oecologia 2012, 170, 313-323. [CrossRef]

18. Zarco-Tejada, P.J.; Gonzalez-Dugo, V.; Williams, L.E.; Suarez, L.; Berni, J.A.J.; Goldhamer, D.; Fereres, E. A PRI-based water stress index combining structural and chlorophyll effects: Assessment using diurnal narrow-band airborne imagery and the CWSI thermal index. Remote Sens. Environ. 2013, 138, 38-50. [CrossRef]

19. Huemmrich, K.F.; Gamon, J.A.; Tweedie, C.E.; Oberbauer, S.F.; Kinoshita, G.; Houston, S.; Kuchy, A.; Hollister, R.D.; Kwon, H.; Mano, M.; et al. Remote sensing of tundra gross ecosystem productivity and light use efficiency under varying temperature and moisture conditions. Remote Sens. Environ. 2010, 114, 481-489. [CrossRef]

20. Zhang, Q.; Chen, J.M.; Ju, W.M.; Wang, H.M.; Qiu, F.; Yang, F.T.; Fan, W.L.; Huang, Q.; Wang, Y.P.; Feng, Y.K.; et al. Improving the ability of the photochemical reflectance index to track canopy light use efficiency through differentiating sunlit and shaded leaves. Remote Sens. Environ. 2017, 194, 1-15. [CrossRef]

21. Ryu, Y.; Berry, J.A.; Baldocchi, D.D. What is global photosynthesis? History, uncertainties and opportunities. Remote Sens. Environ. 2019, 223, 95-114. [CrossRef]

22. Gamon, J.A.; Penuelas, J.; Field, C.B. A narrow-waveband spectral index that tracks diurnal changes in photosynthetic efficiency. Remote Sens. Environ. 1992, 41, 35-44. [CrossRef]

23. Wong, C.Y.S.; Gamon, J.A. The photochemical reflectance index provides an optical indicator of spring photosynthetic activation in evergreen conifers. New Phytol. 2015, 206, 196-208. [CrossRef] [PubMed]

24. Soudani, K.; Hmimina, G.; Dufrene, E.; Berveiller, D.; Delpierre, N.; Ourcival, J.M.; Rambal, S.; Joffre, R. Relationships between photochemical reflectance index and light-use efficiency in deciduous and evergreen broadleaf forests. Remote Sens. Environ. 2014, 144, 73-84. [CrossRef]

25. Filella, I.; Porcar-Castell, A.; Munne-Bosch, S.; Back, J.; Garbulsky, M.F.; Penuelas, J. PRI assessment of long-term changes in carotenoids/chlorophyll ratio and short-term changes in de-epoxidation state of the xanthophyll cycle. Int. J. Remote Sens. 2009, 30, 4443-4455. [CrossRef]

26. Verrelst, J.; Schaepman, M.E.; Koetz, B.; Kneubuhler, M. Angular sensitivity analysis of vegetation indices derived from CHRIS/PROBA data. Remote Sens. Environ. 2008, 112, 2341-2353. [CrossRef]

27. Cernicharo, J.; Verger, A.; Camacho, F. Empirical and Physical Estimation of Canopy Water Content from CHRIS/PROBA Data. Remote Sens. 2013, 5, 5265-5284. [CrossRef]

28. Yu, G.R.; Chen, Z.; Piao, S.L.; Peng, C.H.; Ciais, P.; Wang, Q.F.; Li, X.R.; Zhu, X.J. High carbon dioxide uptake by subtropical forest ecosystems in the East Asian monsoon region. Proc. Natl. Acad. Sci. USA 2014, 111, 4910-4915. [CrossRef] [PubMed]

29. Nakaji, T.; Kosugi, Y.; Takanashi, S.; Niiyama, K.; Noguchi, S.; Tani, M.; Oguma, H.; Nik, A.R.; Kassim, A.R. Estimation of light-use efficiency through a combinational use of the photochemical reflectance index and vapor pressure deficit in an evergreen tropical rainforest at Pasoh, Peninsular Malaysia. Remote Sens. Environ. 2014, 150, 82-92. [CrossRef]

30. Zheng, G.; Moskal, L.M.; Kim, S.H. Retrieval of Effective Leaf Area Index in Heterogeneous Forests with Terrestrial Laser Scanning. IEEE Trans. Geosci. Remote Sens. 2013, 51, 777-786. [CrossRef]

31. Lim, K.; Treitz, P.; Wulder, M.; St-Onge, B.; Flood, M. LiDAR remote sensing of forest structure. Prog. Phys. Geogr. 2003, 27, 88-106. [CrossRef]

32. Bienert, A.; Scheller, S.; Keane, E.; Mohan, F.; Nugent, C. Tree detection and diameter estimations by analysis of forest terrestrial laserscanner point clouds. In Proceedings of the ISPRS Workshop on Laser Scanning, Espoo, Finland, 12-14 September 2007; pp. 50-55.

33. Brolly, G.; Király, G. Algorithms for stem mapping by means of terrestrial laser scanning. Acta Silvatica et Lignaria Hungarica 2009, 5, 119-130.

34. Király, G.; Brolly, G. Tree height estimation methods for terrestrial laser scanning in a forest reserve. Int. Arch. Photogramm. Remote Sens. Spat. Inf. Sci. 2007, 36, 211-215.

35. Ma, L.X.; Zheng, G.; Eitel, J.U.H.; Magney, T.S.; Moskal, L.M. Retrieving forest canopy extinction coefficient from terrestrial and airborne lidar. Agric. For. Meteorol. 2017, 236, 1-21. [CrossRef]

36. Ma, L.X.; Zheng, G.; Wang, X.F.; Li, S.M.; Lin, Y.; Ju, W.M. Retrieving forest 'canopy clumping index using terrestrial laser scanning data. Remote Sens. Environ. 2018, 210, 452-472. [CrossRef] 
37. Coops, N.C.; Hermosilla, T.; Hilker, T.; Black, T.A. Linking stand architecture with canopy reflectance to estimate vertical patterns of light-use efficiency. Remote Sens. Environ. 2017, 194, 322-330. [CrossRef]

38. Chunlin, W.; Guoyi, Z.; Xu, W.; Xuli, T.; Chuanyan, Z.; Guirui, Y.J.A.E.S. Below-canopy $\mathrm{CO}_{2}$ flux and its environmental response characteristics in a coniferous and broad-leaved mixed forest in Dinghushan, China. Acta Ecol. Sin. 2007, 27, 846-853. [CrossRef]

39. Wang, C.; Yu, G.; Zhou, G.; Yan, J.; Zhang, L.; Wang, X.; Tang, X.; Sun, X. $\mathrm{CO}_{2}$ flux evaluation over the evergreen coniferous and broad-leaved mixed forest in Dinghushan, China. Sci. China Ser. D Earth Sci. 2006, 49, 127-138. [CrossRef]

40. Guo-yi, L.J.X.Z.; Qian-mei, C.G.W.Z. Effects of soil acidity on the soil nutrients under Dinghushan monsoon evergreen broad-leaved forest. Acta Pedol. Sin. 2003, 40, 767-773.

41. Liu, J.C.; Zhou, G.Y.; Zhang, D.Q. Simulated effects of acidic solutions on element dynamics in monsoon evergreen broad-leaved forest at Dinghushan, China. Part 1: Dynamics of K, Na, Ca, Mg and P. Environ. Sci. Pollut. Res. 2007, 14, 123-129. [CrossRef]

42. Roujean, J.L.; Leroy, M.; Deschamps, P.Y. A bidirectional reflectance model of the Earth's surface for the correction of remote sensing data. J. Geophys. Res. Atmos. 1992, 97, 20455-20468. [CrossRef]

43. Hilker, T.; Coops, N.C.; Hall, F.G.; Black, T.A.; Wulder, M.A.; Nesic, Z.; Krishnan, P. Separating physiologically and directionally induced changes in PRI using BRDF models. Remote Sens. Environ. 2008, 112, 2777-2788. [CrossRef]

44. Liu, L.Y.; Guan, L.L.; Liu, X.J. Directly estimating diurnal changes in GPP for C3 and C4 crops using far-red sun-induced chlorophyll fluorescence. Agric. For. Meteorol. 2017, 232, 1-9. [CrossRef]

45. Hall, F.G.; Hilker, T.; Coops, N.C.; Lyapustin, A.; Huemmrich, K.F.; Middleton, E.; Margolis, H.; Drolet, G.; Black, T.A. Multi-angle remote sensing of forest light use efficiency by observing PRI variation with canopy shadow fraction. Remote Sens. Environ. 2008, 112, 3201-3211. [CrossRef]

46. Hilker, T.; van Leeuwen, M.; Coops, N.C.; Wulder, M.A.; Newnham, G.J.; Jupp, D.L.B.; Culvenor, D.S. Comparing canopy metrics derived from terrestrial and airborne laser scanning in a Douglas-fir dominated forest stand. Trees-Struct. Funct. 2010, 24, 819-832. [CrossRef]

47. Garbulsky, M.F.; Penuelas, J.; Gamon, J.; Inoue, Y.; Filella, I. The photochemical reflectance index (PRI) and the remote sensing of leaf, canopy and ecosystem radiation use efficiencies A review and meta-analysis. Remote Sens. Environ. 2011, 115, 281-297. [CrossRef]

48. Urban, O.; Klem, K.; Ac, A.; Havrankova, K.; Holisova, P.; Navratil, M.; Zitova, M.; Kozlova, K.; Pokorny, R.; Sprtova, M.; et al. Impact of clear and cloudy sky conditions on the vertical distribution of photosynthetic $\mathrm{CO}_{2}$ uptake within a spruce canopy. Funct. Ecol. 2012, 26, 46-55. [CrossRef]

49. Cheng, S.J.; Bohrer, G.; Steiner, A.L.; Hollinger, D.Y.; Suyker, A.; Phillips, R.P.; Nadelhoffer, K.J. Variations in the influence of diffuse light on gross primary productivity in temperate ecosystems. Agric. For. Meteorol. 2015, 201, 98-110. [CrossRef]

50. Anderson, M.C.; Miller, E.E. Forest Cover as a Solar Camera - Penumbral Effects in Plant Canopies. J. Appl. Ecol. 1974, 11, 691-697. [CrossRef]

51. Sandmeier, S.; Muller, C.; Hosgood, B.; Andreoli, G. Physical mechanisms in hyperspectral BRDF data of grass and watercress. Remote Sens. Environ. 1998, 66, 222-233. [CrossRef]

52. Barton, C.V.M.; North, P.R.J. Remote sensing of canopy light use efficiency using the photochemical reflectance index-Model and sensitivity analysis. Remote Sens. Environ. 2001, 78, 264-273. [CrossRef]

(C) 2020 by the authors. Licensee MDPI, Basel, Switzerland. This article is an open access article distributed under the terms and conditions of the Creative Commons Attribution (CC BY) license (http://creativecommons.org/licenses/by/4.0/). 